\title{
ORIENTASI PADA PRA PLOTTING PETA BERSISTEM KOORDINAT LOKAL TERHADAP SISTEM KOORDINAT FIX (TETAP)
}

\author{
Yuwono $^{1)}$, AdiKurniawan ${ }^{2)}$ \\ 1) Jurusan Teknik Geomatika, ITS, ${ }^{2)}$ Jurusan Teknik Sistem Perkapalan, ITS \\ Email: yuwono@geodesy.its.ac.id
}

\begin{abstract}
Abstrak. Untuk berbagai keperluan perencanaan dan pelaksanaan suatu pekerjaan teknis, sering peta (topografi) yang ada dikeluhkan tidak cocok. Ada berbagai penyebab ketidakcocokan peta tersebut antara lain adalah masalah orientasi. Penggunaan orientasi sangat penting dalam sebuah peta, artinya apabila terjadi kesalahan orientasi atau arah, maka akan terjadi ketidak cocokan antara rencana dan kenyataan di lapangan. Sebagai contoh di peta diperkirakan masih berupa lahan kosong, sehingga direncanakan peruntukannya misalnya untuk perumahan, tetapi setelah dilakukan penerapan di lapangan ternyata pada daerah tersebut bukan lagi lahan kosong akan tetapi sungai. Hal ini akan mengakibatkan kesan bahwa peta tersebut tidak cocok, padahal dapat terjadi bahwa permasalahannya ada pada orientasi saja.
\end{abstract}

Kata Kunci: peta; koordinat; orientasi

Abstract. Topographic map is needed in many design and technical application, unfortunately the map often get a complainor the map is not inconsistent. There are many caused about inconsistant in a map, one of them is about orientation. Orientation is very important for a map, if the map orientation is mistake, it will cause inconsistent between design and real condition in field. For example, in a map it seem blank area, so this area available to be designed for housing. In real field condition the area is not blank area, but river. This case will cause the map can not available to use for design or the map inconsistant. Really, the problem could be in orientation only.

Keyword: map; coordinates; orientation

\section{PENDAHULUAN}

Peta merupakan sumber informasi. Sumber informasi ini dapat dibedakan menurut sifatnya yaitu peta topografi dan peta tematik. Peta topografi merupakan gambaran dari sebagian atau seluruh permukaan bumi yang terletak pada bidang datar dan memuat unsur-unsur alam dan atau unsur buatan manusia dengan skala tertentu dan cara tertentu (Yuwono, 2000). Sedangkan peta tematik adalah peta yang menonjolkan tema tertentu (misalnya jaringan air minum, jaringan jalan, jaringan listrik, penggunaan lahan dan sebagainya), umumnya peta ini memerlukan latar belakang topografi juga walaupun tidak semua unsur pada topografi dimuat semuanya (Aziz, 1980).

Sebagai sumber informasi, maka peta harus menunjukkan sesuatu yang benar. Peta yang baik atau yang ideal (lebih tepat mendekati ideal) apabila dipenuhi hal-hal sebagai berikut, yaitu jaraknya benar, arahnya benar, luasnya benar, dan bentuknya benar.

Untuk penunjukan arah, dalam peta biasa digunakan sudut jurusan atau "mata angin", misalnya 20 derajat dari arah Utara atau arah Timur, Barat dan sebagainya. Penunjukkan arah yang salah pada pembuatan peta akan mengakibatkan kesalahan pada penggunaan peta tersebut. Hal ini menyebabkan tidak tercapainya informasi dari peta sebagai sumber informasi.

\section{Orientasi Peta}

Orientasi peta dimaksudkan dengan arah acuan dari peta yang digunakan. Peta (topografi) menggunakan orientasi yang fix terhadap arah utara peta. Arah ini selalu dikaitkan dengan sistem koordinat (salib sumbu) $X$ dan $Y$ pada bidang datar. Ketentuan yang berlaku adalah sumbu $Y+$ sebagai arah utara dan sumbu $X+$ sebagai arah timur. 
Untuk dapat mengetahui arah dari suatu objek (yang diwakili oleh koordinat satu atau beberapa titik) digunakan acuan terhadap arah dari utara. Arah ini dapat dihitung berdasarkan sudut jurusan. Penggunaan sudut jurusan terkait dengan sistem salib sumbu. Salib sumbu harus mempunyai satu sistem untuk satu lokasi pemetaan. Apabila karena sesuatu hal tidak dimungkinkan dengan satu salib sumbu, maka dapat digunakan salib sumbu sementara sebagai tambahan, tetapi tahap berikutnya salib sumbu sementara ini harus "digabungkan" dengan salib sumbu yang fix. Cara menggabungkannya dengan mengorientasikan terhadap salib sumbu yang fix.

\section{Sistem Koordinat}

Sistem koordinat yang digunakan pada peta ada beberapa macam antara sistem koordinat Geografis, Kartesian, baik dua demensi maupun tiga demensi, dan sebagainya. Selanjutnya yang dibicarakan disini adalah koordinat kartesian dua dimensi.

Dalam suatu area pemetaan, sistem kordinat yang dibangun hanyalah satu sistem, akan tetapi apabila dengan satu sistem tersebut secara langsung tidak memungkinkan untuk dilakukan, maka dapat dibuat satu sistem koordinat lagi. Namun demikian sistem koordinat yang kedua ini nantinya harus ditransformasi ke sistem koordinat yang digunakan sebagai acuan atau referensi. Transformasi koordinat dapat hanya berupa rotasi saja apabila titik awalnya sama.

Sebagai ilustrasi, lihat Gambar 1:

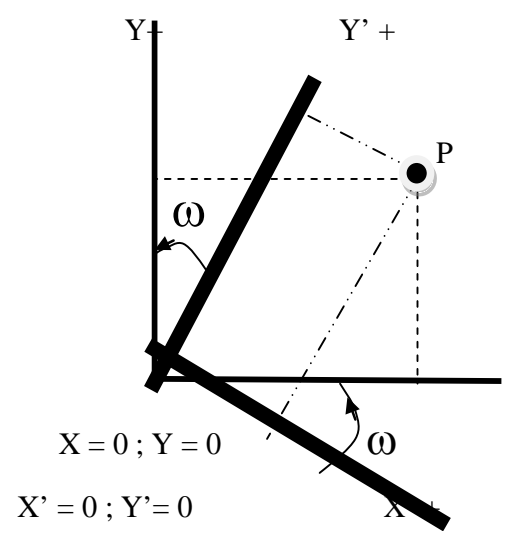

Gambar 1. Salib Sumbu dan Sudut Rotasi
Keterangan:

Salib sumbu $X$ dan $Y$ adalah salib sumbu yang baku;

Salib sumbu $X^{\prime}$ dan $Y^{\prime}$ adalah salib sumbu sementara (lokal);

Sudut rotasi sebesar $\omega$ kearah kiri (searah jarum jam).

Matriks yang digunakan untuk menghitung rotasi adalah sebagai berikut (Wolf, 1974):

$$
\left[\begin{array}{l}
\mathrm{Xp} \\
\mathrm{Yp}
\end{array}\right]=\left[\begin{array}{cc}
\operatorname{Cos} \omega & \operatorname{Sin} \omega \\
-\operatorname{Sin} \omega & \operatorname{Cos} \omega
\end{array}\right]\left[\begin{array}{c}
\mathrm{Xp} \\
\mathrm{Yp}^{\prime}
\end{array}\right]
$$

Keterangan:

$\mathrm{Xp}$ dan Yp merupakan koordinat baru fix titik $\mathrm{P}$ (salib sumbu fix),

$X p^{\prime}$ dan $Y p^{\prime}$ merupakan koordinat lama/lokal titik $P$ (salib sumbu lokal),

$\omega$ merupakan sudut rotasi

Dengan adanya matriks rotasi ini, maka semua titik koordinat dapat dirotasikan ke sistem koordinat kartesian fix dan dapat dilakukan sekaligus, karena ukuran matriks rotasi $(2 \times 2)$ dan ukuran matriks koordinat lokal sebesar $(2 \times n)$ dengan $n$ merupakan jumlah titik koordinat lokal.

\section{Sudut Jurusan}

Sudut jurusan merupakan sudut dimana salah satu sisinya merupakan arah utara. Sudut jurusan ini digunakan untuk menentukan arah, karena acuan sudut jurusan adalah Utara sebagai sudut awal atau titik nol derajatnya. Sudut jurusan antara dua titik dapat dihitung dengan rumus (Mikhail, 1982 ).

$$
\begin{aligned}
& \text { Sudut Jurusan } A B=\alpha A B \\
& =\operatorname{Arctan}\{(X B-X A) /(Y B-Y A)\}
\end{aligned}
$$

\section{Keterangan:}

$X A, Y A$ merupakan koordinat titik $A$

$X B, Y B$ merupakan koordinat titik B

Arc tan merupakan fungsi goneometri 
Pengertian sudut jurusan dapat dilihat seperti pada Gambar 2 berikut ini;

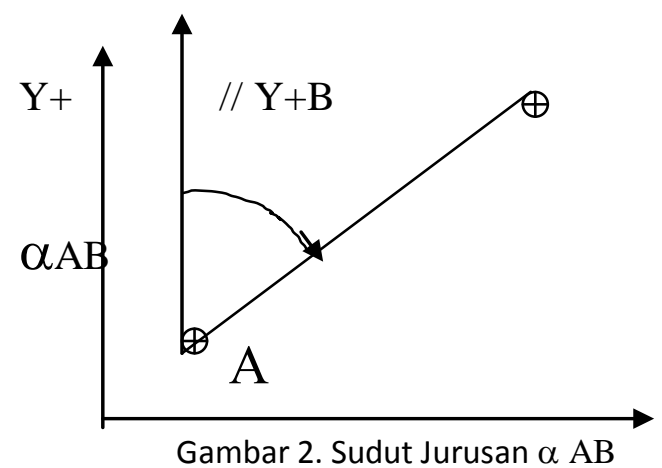

Sumbu $\mathrm{Y}_{+}$merupakan arah Utara pada peta, selanjutnya dihitung arah dari titik A ke titik B melalui arah Utara. Arah Utara dapat dibuat pada setiap titik dengan mengacu ke kesejajaran arah Utara tersebut, sehingga setiap titik dapat ditentukan arahnya terhadap titik lainnya (sudut jurusannya). Sebagai contoh adalah sudut jurusan $A B$ yaitu arah dari $A$ ke $B$ (apabila koordinat titik $A$ dan $B$ diketahui) terhadap arah orientasi peta (arah Utara), besarnya arah atau sudut jurusan sesuai dengan rumus

$$
\alpha A B=\arctan \{(X B-X A) /(Y B-Y A)\}
$$

\section{Permasalahan}

Bagaimana mengorientasikan peta apabila titik fix tidak saling terlihat

\section{METODOLOGI}

Metodologi yang digunakan pada dasarnya menjelaskan bagaimana penelitian ini dilakukan. Materi pokok pada bagian ini adalah: (1) menghitung orientasi antara dua titik fix yang tidak saling terlihat; (2) menambah titik koordinat untuk membantu menghitung orientasi lokal; (3) mencari besarnya sudut rotasi; (4) mengorientasikan salib sumbu koordinat sesuai dengan besarnya sudut rotasi.

Penggunaan titik fix (titik yang telah mempunyai koordinat $(x, y)$ tertentu) yang saling tidak terlihat pada daerah yang dipetakan berjumlah minimum 2 (dua) buah titik, misalnya titik pertama titik A dan titik yang kedua titik B. Dari dua titik ini dapat dihitung arah orientasi dengan menggunakan sudut jurusan, yaitu sudut yang salah satu sisinya merupakan arah Utara. Arah Utara ini selalu digunakan untuk orientasi peta.

Referensi horisontal, untuk sederhananya dibuat tidak di bidang ellipsoid, tetapi di bidang datar $(x, y)$ yang merupakan bidang proyeksi (Vanicek, 1982), mengingat daerah yang relatif kecil atau tidak luas (jarak terpanjang $<55 \mathrm{Km}$ ), lebih mudah menggunakan bidang datar.

Selanjutnya perlu menghitung sudut jurusan antara titik fix tersebut berdasarkan orientasi lokal dengan cara menambah titik bantu, misalnya titik $\mathrm{C}$. Orientasi dari titik $\mathrm{A}$ ke titik $\mathrm{C}$ dibuat dengan sudut jurusan lokal sebesar $00^{\prime} 0^{\prime \prime}$ (arah Utara lokal). Dengan melakukan pengukuran jarak dari A ke C dan dari $C$ ke $B$ serta mengukur sudut di titik $C$ dan menentukan koordinat $(x, y)$ titik $A$ sebesar $(0,0)$ meter, maka nilai koordinat titik $C$ dan $B$ dengan sistem koordinat lokal dapat dihitung. Di samping itu dapat juga dihitung sudut jurusan lokal antara titik A dan B.

Hasil koordinat lokal titik A, B, dan C dapat digunakan untuk pemetaan dengan sistem koordinat lokal. Untuk mengorientasikan peta tersebut terhadap koordinat yang fix, maka harus dicari besarnya sudut rotasi pada titik $A$. Sudut rotasi ( = $\omega$ ) dapat dihitung berdasarkan selisih sudut jurusan antara titik $A B$ yang mempunyai koordinat fix dan sudut jurusan antara titik $A B$ yang mempunyai koordinat lokal.

Untuk menghitung seluruh koordinat yang dipetakan dengan sistem koordinat lokal menjadi koordinat fix dibutuhkan rotasi sebesar sudut $\omega$, yaitu dengan mengalikan matriks koordinat lokal dengan matriks rotasi.

Sebagai gambaran dari uraian metodologi di atas, maka berikut ini ditunjukkan visualisasi secara skematik dari metodologi tersebut pada Gambar 3. 


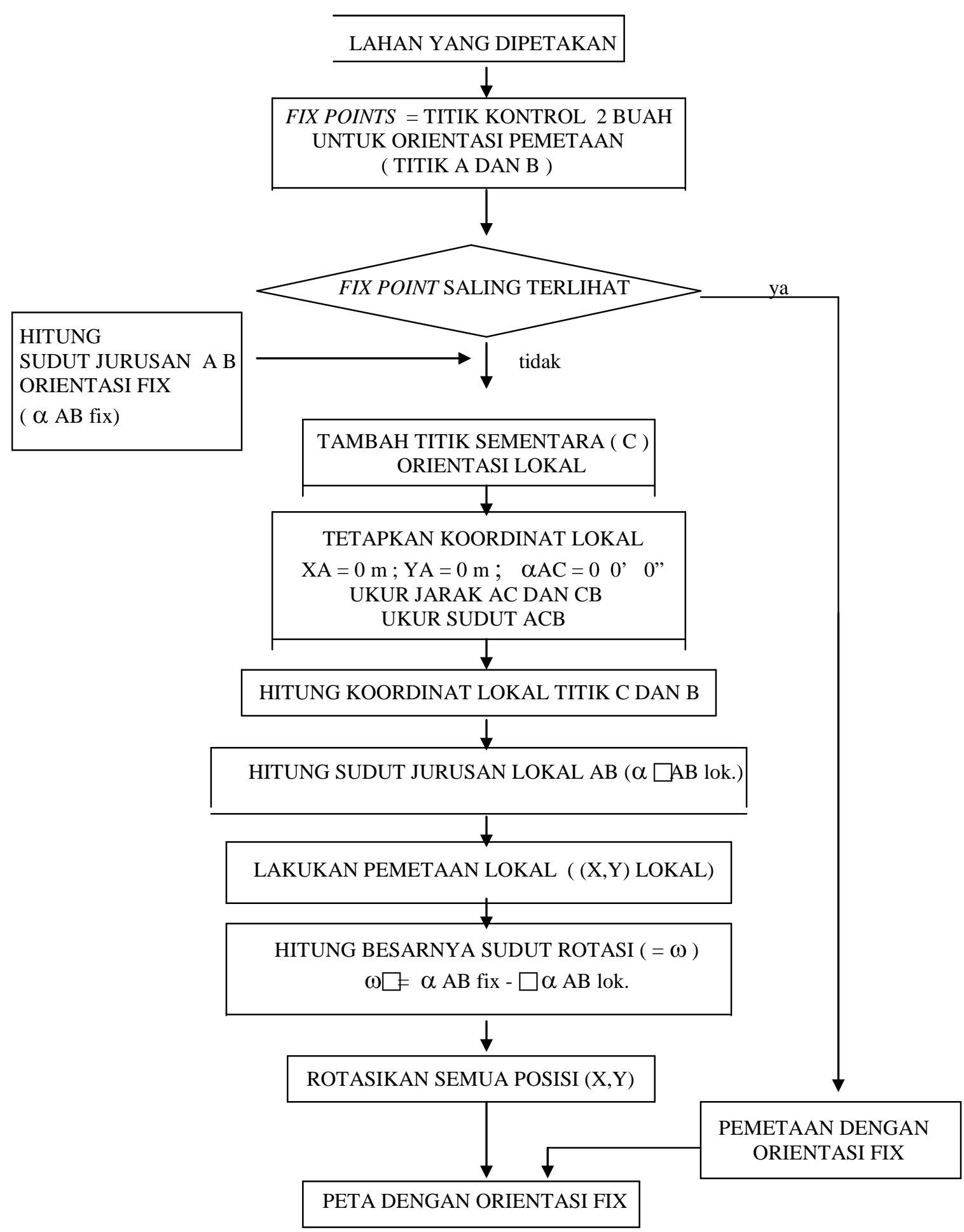

Gambar 3. Visualisasi Skematik Orientasi Hasil (Koordinat - Peta) 


\section{Contoh Kasus:}

Diketahui koordinat titik fix:

$$
\begin{aligned}
& A(X A=0,000 m \text { dan } Y A=0,000 m) \text { dan } \\
& B(X B=150,000 m \text { dan } Y B=-50,000 m) .
\end{aligned}
$$

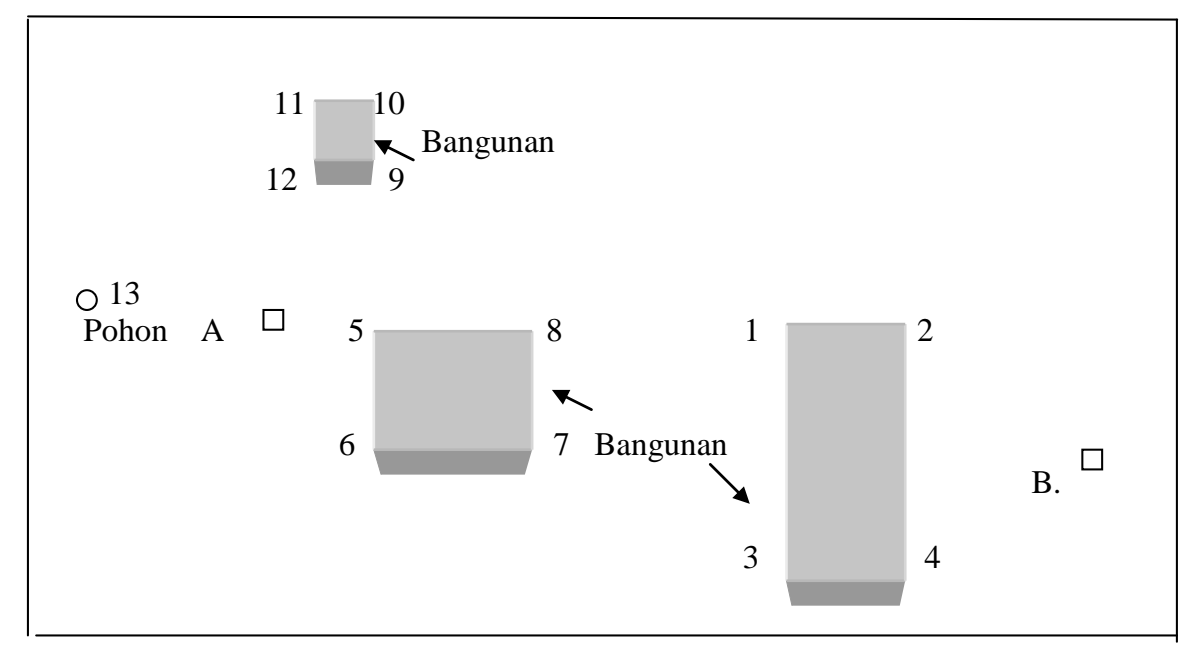

Gambar 4. Posisi Titik Fix A dan B dan Bangunan yang Menghalangi

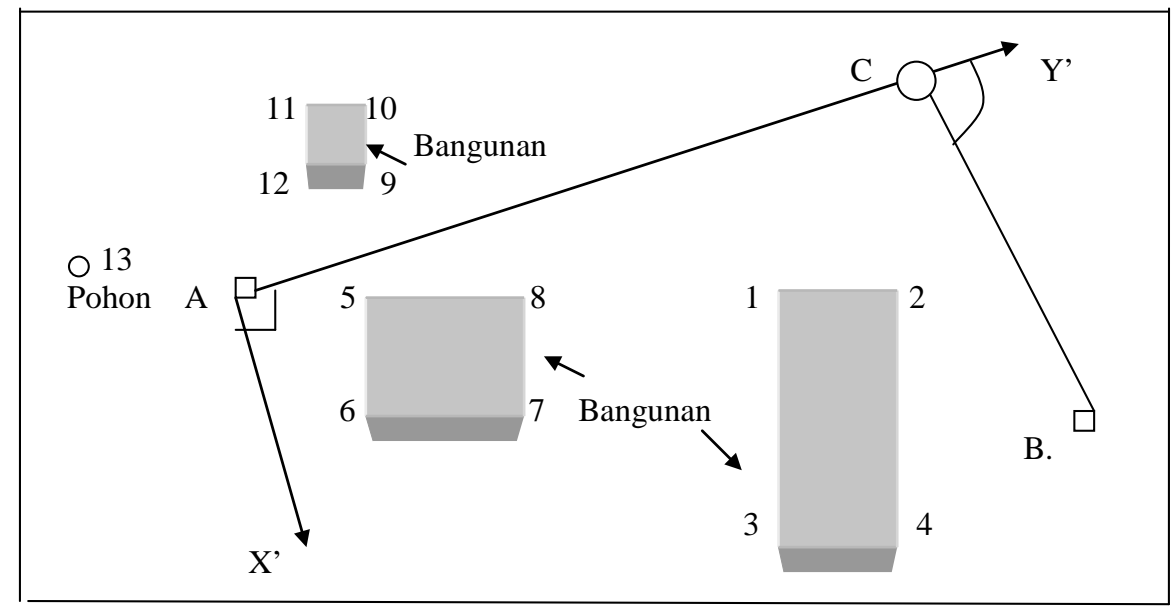

Gambar 5. Posisi Titik Bantu C 
Data koordinat yang diperoleh dengan sistem koordinat lokal, seperti terlihat pada Tabel 1 berikut ini.

Tabel 1. Koordinat Obyek dengan Sistem Koordinat Lokal

\begin{tabular}{crrc}
\hline No. & \multicolumn{1}{c}{$X(\mathrm{~m})$} & \multicolumn{1}{c}{$Y(\mathrm{~m})$} & Keterangan \\
\hline A & 0,000 & 0,000 & Titik tetap (fix) \\
B & 90,994 & 129,306 & Titik tetap (fix) \\
1 & 43,000 & 70,000 & Pojok Bangunan \\
2 & 48,000 & 89,000 & Pojok Bangunan \\
3 & 80,000 & 58,000 & Pojok Bangunan \\
4 & 86,000 & 78,000 & Pojok Bangunan \\
5 & 18,000 & 25,000 & Pojok Bangunan \\
6 & 37,000 & 19,000 & Pojok Bangunan \\
7 & 43,000 & 58,000 & Pojok Bangunan \\
8 & 24,000 & 44,000 & Pojok Bangunan \\
9 & $-39,000$ & 43,000 & Pojok Bangunan \\
10 & $-48,000$ & 45,000 & Pojok Bangunan \\
11 & $-51,000$ & 36,000 & Pojok Bangunan \\
12 & $-42,000$ & 33,000 & Pojok Bangunan \\
13 & $-23,000$ & $-5,000$ & Pohon \\
\hline
\end{tabular}

Tahap pertama yang dilakukan adalah menambah titik $C$ yang letaknya sedemikian rupa sehingga titik ini dapat dilihat dari titik A dan $B$. Ukur jarak AC misalnya $=104,403 \mathrm{~m}$ dan jarak $B C=94,340 \mathrm{~m}$. Sudut di titik $C$ tersebut sebesar 254 '41' 37,9".

Tahap kedua menghitung sudut jurusan $A B$ yang fix :

$$
\begin{aligned}
\alpha \mathrm{AB} \text { fix } & =\arctan \{(\mathrm{XB}-\mathrm{XA}) /(\mathrm{YB}-\mathrm{YA})\} \\
& =\arctan \{(150-0) /(-50-0)\} \\
& =108^{\circ} 26^{\prime} 5,82^{\prime \prime} \\
& \text { (terletak di kuadran II) }
\end{aligned}
$$

Tahap ketiga membuat salib sumbu lokal $X^{\prime}$ dan $Y^{\prime}$ yang berpedoman pada sumbu $Y^{\prime}$ pada jalur $A C$.

Tahap keempat hitung koordinat titik C dan B berdasarkan salib sumbu lokal dengan koordinat titik $A$ bernilai $X A=0$ meter dan $Y A=0$ meter.

Hitungan koordinat titik $C$ :

$$
\begin{aligned}
X C & =X A+d A C \operatorname{Sin} \alpha A C \\
& =0+104,403 * \operatorname{Sin}(0) \\
& =0 \text { meter }
\end{aligned}
$$

$$
\begin{aligned}
Y C & =Y A+d A C \operatorname{Cos} \alpha A C \\
& =0+104,403 * \operatorname{Cos}(0) \\
& =104,403 \text { meter }
\end{aligned}
$$

Hitungan koordinat titik $B$ :

$$
\begin{aligned}
X B & =X C+d C B \operatorname{Sin} \alpha C B \\
& =0+94,340^{*} \operatorname{Sin}\left(74^{\circ} 41^{\prime} 37,9^{\prime \prime}\right) \\
& =90,994 \text { meter } \\
Y B & =Y C+d C B \operatorname{Cos} \alpha C B \\
& =104,403+94,340 * \operatorname{Cos}\left(74^{\circ} 41^{\prime} 37,9^{\prime \prime}\right) \\
& =129,306 \text { meter }
\end{aligned}
$$

Tahap kelima menghitung sudut jurusan $A B$ berdasarkan koordinat lokal,

$\alpha$ AB lokal

$$
\begin{aligned}
& =\arctan \{(\mathrm{XB}-\mathrm{XA}) /(\mathrm{YB}-\mathrm{YA})\} \\
& =\arctan \{(90,994-0) /(129,306-0)\} \\
& =35^{\circ} 08^{\prime} 4,04^{\prime \prime} \text { (terletak di kuadran I) }
\end{aligned}
$$

Tahap keenam menghitung besarnya sudut rotasi $(=\omega)$

$$
\begin{aligned}
\omega & =\alpha \text { AB fix }-\alpha \text { AB lokal } \\
& =108^{\circ} 26^{\prime} 5,82^{\prime \prime}-35^{\circ} 08^{\prime} 4,04^{\prime \prime} \\
& =108^{\circ} 26^{\prime} 5,82^{\prime \prime}-35^{\circ} 08^{\prime} 4,04^{\prime \prime} \\
& =73^{\circ} 18^{\prime} 01,78^{\prime \prime}
\end{aligned}
$$

\section{HASIL DAN PEMBAHASAN}

Berdasarkan koordinat dengan sistem koordinat lokal di atas dan telah dihasilkannya besar sudut rotasi, maka dapat dihitung besarnya koordinat fix terhadap salib sumbu fix $(X, Y)$.

Dengan menggunakan rumus matriks rotasi,

$$
\left[\begin{array}{l}
\mathrm{Xp} \\
\mathrm{Yp}-
\end{array}\right]=\left[\begin{array}{cc}
\operatorname{Cos} \omega & \operatorname{Sin} \omega \\
\operatorname{Sin} \omega & \operatorname{Cos} \omega
\end{array}\right]\left[\begin{array}{c}
\mathrm{Xp} \\
\mathrm{Yp}
\end{array}\right]
$$

dan besarnya sudut rotasi $\omega=73^{\circ} 18^{\prime} \quad 01,78^{\prime \prime}$, maka besarnya koordinat yang baru (fix) dapat dilihat pada Tabel 2 di halaman berikut ini. 
Tabel 2. Koordinat Hasil Rotasi

\begin{tabular}{crrc}
\hline No. & \multicolumn{1}{c}{ X $(\mathrm{m})$} & \multicolumn{1}{c}{$Y(\mathrm{~m})$} & Keterangan \\
\hline A & 0,000 & 0,000 & Titik fix A \\
B & 150.000 & -50.000 & Titik fix B \\
1 & 79,404 & $-21,072$ & titik 1 \\
2 & 99,039 & $-20,401$ & titik 2 \\
3 & 78,542 & $-59,960$ & titik 3 \\
4 & 99,423 & $-59,960$ & titik 4 \\
5 & 29,118 & $-10,057$ & titik 5 \\
6 & 28,831 & $-29,980$ & titik 6 \\
7 & 48,754 & $-30,267$ & titik 7 \\
8 & 49,041 & $-10,344$ & titik 8 \\
9 & 29,980 & 49,711 & titik 9 \\
10 & 29,309 & 58,906 & titik 10 \\
11 & 19,827 & 59,194 & titik 11 \\
12 & 19,539 & 49,711 & titik 12 \\
13 & $-11,398$ & 20,593 & titik 13 \\
\hline
\end{tabular}

Hasil hitungan besarnya sudut rotasi pada contoh di makalah ini sebesar $\omega=73^{\circ} 18^{\prime}$ 01,78". Putaran dari rotasi ini adalah ke kiri, karena sudut jurusan dari koordinat fix dikurangi dengan sudut jurusan koordinat lokal bernilai atau bertanda positif. Jadi salib sumbu sistem koordinat lokal dibawa atau disesuaikan ke salib sumbu sistem koordinat fix. Rumus yang digunakan adalah :

$$
\left[\begin{array}{l}
\mathrm{Xp} \\
\mathrm{Yp}
\end{array}\right]=\left[\begin{array}{cc}
\operatorname{Cos} \omega & \operatorname{Sin} \omega \\
-\operatorname{Sin} \omega & \operatorname{Cos} \omega
\end{array}\right]\left[\begin{array}{l}
\mathrm{Xp} \\
\mathrm{Yp}^{\prime}
\end{array}\right]
$$

Apabila pengurangan nilai sudut jurusan fix dengan nilai sudut jurusan lokal hasilnya negatif, maka arah putaran rotasi salib sumbunya ke kanan. Untuk rumus yang digunakan akan berbeda, yaitu :

$$
\left[\begin{array}{r}
\mathrm{Xp} \\
\mathrm{Yp}
\end{array}\right]=\left[\begin{array}{cc}
\operatorname{Cos} \omega & -\operatorname{Sin} \omega \\
\operatorname{Sin} \omega & \operatorname{Cos} \omega
\end{array}\right]\left[\begin{array}{c}
\mathrm{Xp} \\
\mathrm{Yp}^{\prime}
\end{array}\right]
$$

Pada waktu dilakukan rotasi, maka semua koordinat dengan sistem lokal akan berubah nilainya, namun demikian yang perlu dicatat adalah semua obyek atau benda atau titik-titik yang ada di lapangan tidak berpindah secara fisik, tetapi hanya berubah nilai koordinat.

Penyatuan sistem koordinat pada suatu peta akan punya arti penting, karena apabila dalam satu peta mempunyai dua sistem koordinat, akan terjadi tumpang tindih obyek atau kekosongan obyek karena ada beberapa obyek yang mengikuti sistem koordinat yang satu dan beberapa obyek lainnya mengikuti sistem koordinat yang lain.

\section{PENUTUP}

\section{Simpulan}

Orientasi yang merupakan bagian dari transformasi koordinat dapat digunakan untuk menyatukan dua sistem koordinat apabila tidak terjadi translasi dan penskalaan. Besarnya sudut rotasi bergantung pada selisih sudut jurusan antara sistem koordinat yang kesatu dengan sistem koordinat yang kedua. Hitungan koordinat hasil rotasi dapat dilakukan dengan simultan (serentak), tidak perlu per titik, dengan menggunakan matriks rotasi.

\section{Saran}

Penggunaan rotasi salib sumbu koordinat perlu hati-hati, karena harus memperhatikan faktor lain yaitu translasi dan penskalaan. Untuk salib sumbu koordinat yang titik asalnya (origin) tidak berimpit antara dua sistem koordinat yang ada, maka faktor translasi dan penskalaan harus diperhitungkan, agar hasil hitungan tidak salah. 


\section{DAFTAR PUSTAKA}

Aziz, Lukman, (1980). Pemetaan Tematik. Bandung: Jurusan Teknik Geodesi Institut Teknologi Bandung.

Mikhail, M.Edward dan Gordon Gracie, (1982). Analysis And Adjustment of Survey Measurements. New York: Van Nostrand Reinhold Company.

Vanicek, P. dan Krakiwsky, E.J., (1982). Geodesy the Concepts. New York.

Wolf, P.R., (1974). Elements of Photogrammetry. McGraw-Hill.

Yuwono, (2000). Kartografi Dasar. (Tidak diterbitkan). Surabaya. 